\title{
On Pancratium maritimum (sea daffodil, sea lily, sand lily)
}

\begin{abstract}
The perennial geophyte sea daffodil, sea lily or sand lily (Pancratium maritimum L.) is a flowering species during the dry summer, widely distributed along Mediterranean seashores and grown in a wild stage. Populations of sea daffodil are exposed to sea breeze, salt spray, water shortage, strong solar radiation, elevated temperatures, substrate instability and moving sand. Also, it is expected that excessive tourism and human-induced activities will constrain the development of populations of $P$. maritimum, which have resulted from a long-term evolutionary process. $P$. maritimum exhibits large white flowers of a great aesthetic value during dry and hot summer weather conditions, when simultaneously flowering plant taxa are scarce. The buds remain protected below the soil surface on the underground perennial organ and the growth period alternates with a period of dormancy. The above-ground organs and tissues are exposed to harsh, ambient conditions and the large inflorescences of remarkable beauty and fragrance carry particular ornamental worth and thus economic value.
\end{abstract}

Keywords: growth, life history, phenology, sea daffodils, seasonality
Volume 2 Issue 3 - 2018

\section{John Pouris, Sophia Rhizopoulou \\ Department of Botany, National and Kapodistrian University of Athens, Greece}

Correspondence: Sophia Rhizopoulou, Department of Botany, Faculty of Biology, National and Kapodistrian University of Athens, Panepistimiopolis, 15784, Athens, Greece, Email srhizop@biol.uoa.gr

Received: December 17, 2017 | Published: June 08, 2018

\section{Introduction}

Pancratium maritimum L. (Amaryllidaceae) is a lily-like plant with daffodil-like leaves. P. maritimum is a bulbous perennial geophyte that is widely distributed, along the coastline of the Mediterranean region, from the Black Sea to part of the Atlantic coast. ${ }^{1-4}$ Coastal habitats are particularly vulnerable, because they change in response to both biotic and abiotic factors and their biodiversity is affected by the effects of sea-level rise and human-induced impacts. ${ }^{5}$ Therefore, populations of $P$. maritimum decrease due to urbanization, tourism development, tourist trampling, alteration, destruction of dune systems and overcollection; ${ }^{6}$ in fact, excess of flowers sampling is seriously threatening the diversity of this species, resulting in a significant decrease of populations of $P$. maritimum. Actually, the flowering season of $P$. maritimum, and therefore the pleasure in seeing its beautiful flowers, begins in June and ends in September, coinciding with the period of excessive tourism in the Mediterranean, and at a time when simultaneously flowering plant taxa are scarce. Also, P. maritimum is receiving much attention from the international scientific community due to its value as a commercial ornamental plant. ${ }^{7-9}$

\section{History}

P. maritimum has been known for at least 2,500 years in Greece and cultural aspects indicate that the plant ornamentation has played an important role in the early civilization..$^{10}$ The beautiful flowers of the sea daffodil are represented on frescos in Crete and Santorini; they are depicted on archaeological murals, known from excavations in Greece, which display detailed naturalistic portraying animals and plants. For example, the beautiful lily frescos in the palace of Knossos (Crete) and the frescos displaying lily-like flowers at Akrotiri on Santorini island can be identified as sea daffodils. ${ }^{10-13}$ Notably, the etymology of the generic name Pancratium is derived from two Greek

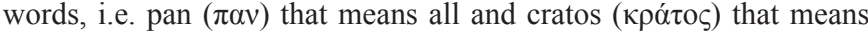
potent. ${ }^{14}$ Also, the sea daffodil is mentioned in Theophrastus' books written in the $3^{\text {rd }}$ century $\mathrm{BC}^{15}$ and Dioscorides' Codex written in the $1^{\text {st }}$ century AD. ${ }^{16}$ It is worth mentioning that a watercolour of $P$. maritimum by the famous artist Ferdinand Bauer (folio 74, produced between 1787 and 1794) was based on specimens collected in Greece in the $18^{\text {th }}$ century, i.e. during the first botanical expedition of Professor John Sibthorp to Greece, ${ }^{17}$ and preserved in the Department of Plant Sciences at Oxford University (UK). A hand-coloured engraving of the above mentioned watercolour of $P$. maritimum (Figure 1 left) is included in $4^{\text {th }}$ volume (published in 1823) of the magnificent Flora Graeca Sibthorpiana (Tabula 309, Hexandria: 6§, Monogynia: 1우), which is currently digitized and electronically accessed; therein, the quoted plant name is P. maritimum and the family (Amaryllidaceae), in accordance to the currently accepted international nomenclature (i.e. in the International Plant Name Index and the Plant List). Although, Pancratium appears as a well-structured group with interesting patterns of speciation, it is worth mentioning that there has been considerable taxonomic confusion in the literature among Pancratium maritimum L., P. linosae Soldano \& F.Conti, P. arabicum Sickenb., $P$. angustifolium Lojac. and $P$. angustifolium M.Roem. ${ }^{18,19}$ Nowadays, it is known that $P$. linosae and $P$. angustifolium are synonyms of $P$. Maritimum..$^{20}$ Notably, P.arabicum falls within the P.maritimum complex and provides new insights to formulate new working hypotheses for evolutionary biology of the genus. ${ }^{21}$ Also, Pancratium is included in a clade with other Eurasian genera of Amaryllidaceae and their phylogenetic relationships reflect the complex geological history of the Mediterranean and neighbouring regions in Asia and Africa. ${ }^{18,22,23}$ Life history characteristics of $P$. maritimum are related to adaptations of this perennial geophyte in response to Mediterranean climatic conditions, because the synanthous $P$. maritimum blossoms during the drought period (i.e. its flowers occur concomitantly with developed foliage). The leaves of $P$. maritimum are amphistomatic, a trait that is known to improve photosynthetic rates and contrast sandblasting. Leaf gas exchange and storage in P. maritimum are also regulated by aerenchyma tissue within leaf inter-vein spaces that acts by maintaining air circulation and relative humidity in leaf tissues and preventing leaf overheating. ${ }^{24}$ Also, leaf adaptation to dry 
coastal environments resulted in vascular elements ensuring efficient water supply to the photosynthetic tissues. ${ }^{24}$ As the flowers open at dusk, ${ }^{25,26}$ release a strong scent during the night. ${ }^{27-30}$ Although, several aspects concerning pollination, pollen morphology, seed dispersal and germination, phytochemistry and genetics of $P$. maritimum have been investigated, ${ }^{31,32}$ there is a scarcity of data on the ecophysiological traits of $P$. maritimum inhabiting maritime sands; therefore, much is still to be discovered. In other words, despite increasing interest in conservation and restoration of $P$. maritimum stands (Figure 1 right), a comparative study on functional traits of the above- and below-ground tissues is still lacking. The associated plant-environment relationships are important to ensure plant survival, especially in stressful habitats, despite the evidence of a direct correlation with climate factors, such as elevated temperatures and low precipitation during the blossoming of $P$. maritimum. Further research is required to illustrate traits contributing to the functional adaptation and response mechanisms of P. maritimum to the fluctuations of the Mediterranean climate.
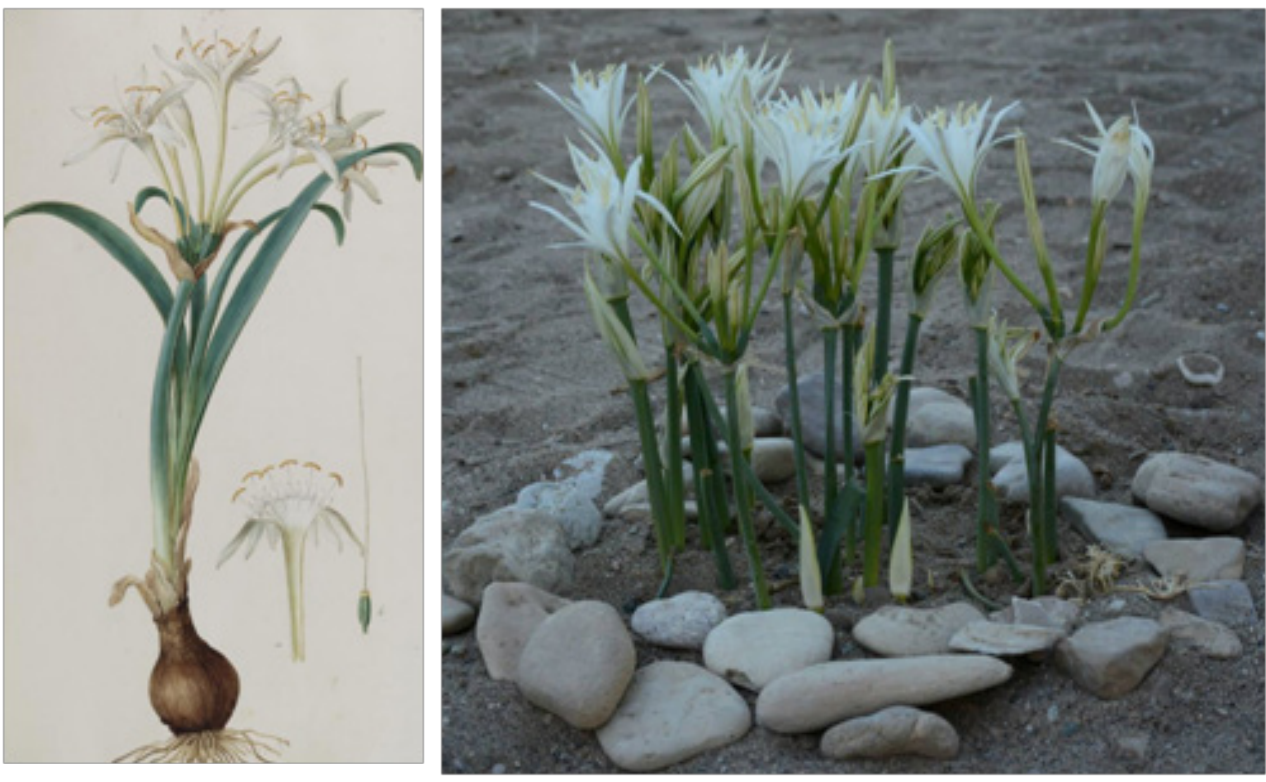

Figure I Pancratium maritimum: (left) drawing by Ferdinand Bauer illustrated in Flora Graeca Sibthorpiana (with permission of the National Library of Greece) and grown in a wild state on the sores of Euboea Island in Greece (right).

\section{Acknowledgements}

None.

\section{Conflict of Interest}

Authors declare that there is no conflict of interest.

\section{References}

1. El Hadidy A, El Ghani MABD, Amer W, et al. Systematic revision of the genus Pancratium L. (Amaryllidaceae) in Egypt with a New Addition. Notulae Scientia Biologicae. 2011;3(2):24-38.

2. Morton JK. The experimental taxonomy of the West African species of Pancratium L. (Amaryllidaceae). Kew Bulletin. 1965;19(2):337-347.

3. Nikopoulos D, Nikopoulou D, Papadopoulou K, et al. Pancratium maritimum ecosystems in Greece. In: Manolas EI, editor. Proceedings of the International Conference on Sustainable Management and Development of Mountainous and Island Areas. University of Crete; 2006:333-340.

4. Balestri E, Cinelli F. Germination and early-seedling establishment capacity of Pancratium maritimum L. (Amaryllidaceae) on coasta dunes in the north-western Mediterranean. Journal of Coastal Research. 2004;20(3):761-770.

5. Farrisa E, Pisanua S, Ceccherellia G, et al. Human trampling effects on Mediterranean coastal dune plants. Plant Biosystems. 2013;147(4):10431051.
6. Farrisa E, Pisanua S, Ceccherellia G, et al. Human trampling effects on Mediterranean coastal dune plants. Plant Biosystems. 2013;147(4):10431051 .

7. Paradiso R, Buonomo R, De Pascale S, et al. Evaluation of spontaneous species for the innovation in floriculture: Pancratium maritimum L. as ornamental plant. Acta Horticulturae. 2009;881:563-566.

8. Dragassaki M, Economou AS, Vlahos JC. Bulblet formation in vitro and plantlet survival extra vitrum in Pancratium maritimum L. Acta Horticulturae. 2001;616:347-352.

9. Demır Z, Müderrısoğlu H, Aksoy N, et al. Effects of second housing and recreational use on Pancratium maritimum L. population in western Black Sea region of Turkey. Journal of Food Agriculture \& Environment. 2010;8(2):890-894.

10. Baumann H. Greek wild flowers and plant lore in ancient Greece. The Herbert Press. London; 1996:170-184.

11. Diapoulis C. Prehistoric plants of the islands of the Aegean sea, sea daffodils (Pancratium maritimum). In: Thera and the Aegean world II. London; 1980:129-139.

12. Tucker AO. Identification of the rose, sage, iris, and lily in the "Blue Bird Fresco" from Knossos, Crete (ca. 1450 BC). Economic Botany. 2004;58(4):733-736.

13. De Cleene M, Lejeune MC. Compendium of symbolic and ritual plans in Europe: Vol I Trees \& Shrubs/Vol II Herbs. Mens \& cultuur uitgevers. Belgium;2003. 
14. Gledhill D. The names of plants. $4^{\text {th }}$ edition. Cambridge Univesity Press. Cambridge; 2008.

15. Negbi M. Theophrastus on geophytes. Botanical Journal of the Linnean Society. 1989;100(1):15-43.

16. Pedanius Dioscorides. De materia medica. Hildesheim; New york: OlmsWeidmann, 2005.

17. Rhizopoulou S. Symbolic plant(s) of the Olympic Games. J Exp Bot. 2004;55(403):1601-1606

18. De Castro O, Brullo S, Colombo P, et al. Phylogenetic and biogeographical inferences for Pancratium (Amaryllidaceae), with an emphasis on the Mediterranean species based on plastid sequence data. Botanical Journal of the Linnean Society. 2012;170(1):12-28.

19. Giovino A, Domina G, Bazan G, et al. Taxonomy and conservation of Pancratium maritimum (Amaryllidaceae) and relatives in the Central Mediterranean. Acta Botanica Gallica. 2015;162(4):289-299.

20. The Plant List.

21. Meerow AW, Snijman DA. The never-ending story: multigene approaches to the phylogeny of Amaryllidaceae, and assessing its familial limits. Aliso. 2006;22:355-366.

22. Koumpli Sovantzi L, Yannitsaros A. A contribution to the coastal flora of the Kikladhes (Greece). Willdenowia. 1993;23(1/2):121-135.

23. Spanou S, Verroios G, Dimitrellos G, et al. Notes on flora and vegetation of the sand dunes of western Greece. Willdenowia. 2006;36(1):235-246.
24. Perrone R, Salmeri C, Brullo S, et al. What do leaf anatomy and micromorphology tell us about the psammophilous Pancratium maritimum L. (Amaryllidaceae) in response to sand dune conditions?. Flora. 2015;213:20-31.

25. Shmida A, Dafni A. Blooming strategies, flower size and advertising in the lily-group geophytes in Israel. Herbertia. 1989;45(1):111-112.

26. Medrano M, Guitián P, Guitián J. Breeding system and temporal variation in fecundity of Pancratium maritimum L. (Amaryllidaceae): reproductive ecology of Pancratium maritimum. Flora. 1999;194(1):13-19.

27. Youssef DTA, Frahm AW. Alkaloids of the flowers of Pancratium maritimum. Planta Med. 1998;64(7):669-670.

28. Berkov S, Evstatieva L, Popov S. Alkaloids in bulgarian Pancratium maritimum L. Z Naturforsch C. 2004;59(1-2):65-69.

29. Asolkar RN, Kamat VP, Kirtany JK. Synthesis of maritimin, a chromone from Pancratium maritimum. Journal of Chemical Research. 2001;12:549-550.

30. Soltan MM, Hamed AR, Hetta MH, et al. Egyptian Pancratium maritimum L. flowers as a source of anti-Alzheimer's agents. Bulletin of Faculty of Pharmacy, Cairo University. 2015;53(1):19-22.

31. Kilinc M, Yuksel S. A morphological, anatomical and ecological study on Pancratium maritimum L. (Amaryllidaceae). Turkish Journal of Botany. 1995; 19:309-320

32. Konyar ST. Ultrastructural aspects of pollen ontogeny in an endangered plant species, Pancratium maritimum L. (Amaryllidaceae). Protoplasma. 2017;254(2):881-900. 